\title{
O DESIGN COMO FERRAMENTA PARA A MELHORIA DO PADRÃO DE QUALIDADE DAS VEDAÇÕES VERTICAIS INTERNAS DE CHAPAS DE MADEIRA MINERALIZADA
}

\author{
Maiara G. D. Camillo - Mestre. Maiara.camillo@univali.br \\ UNIVALI \\ Mayara Atherino Macedo - Mestranda. M.atherinomacedo@gmail.com \\ PPGEP/UFSC \\ Nelson Casarotto Filho - Doutor. Nelson.casarotto@ufsc.br \\ PPGEP/UFSC
}

Resumo: O cronograma da construção de um imóvel geralmente é pré-disposto a aumentos nos prazos por uma dependência ao trabalho manual dos funcionários. $\mathrm{O}$ ato de construir uma habitação é dispendioso e, no seu final, acumula um grande desperdício de material de construção. Desta maneira, o designer entra na área da construção habitacional com o objetivo de auxiliar profissionais de arquitetura e engenharia civil elaborando projetos de produtos industrialmente concebidos, facilitando assim as etapas construtivas. Um dos processos que mais demanda tempo para a execução e é grande produtor de entulhos é o da construção das vedações verticais, inclusive as localizadas internamente no imóvel, seja ele casa ou apartamento. O tempo e a geração de entulho podem ser reduzidos com a utilização das vedações verticais internas industrializadas. Este artigo aborda, então, as características da vedação vertical interna do sistema construtivo que utiliza das chapas de madeira mineralizadas, denominado internacionalmente como wwcb - wood wool cement board. As chapas de madeira mineralizada chamam a atenção, quando por apresentar-se no mercado como um eco-produto. Composta por madeira de reflorestamento ou refugo de empresas de móveis e madeireiras, ela compõe um projeto de produto para vedar eficiente. Isso abre os olhos dos profissionais da área do design ligados à habitação por mostrar-se um bom aliado pela busca pela sustentabilidade na construção de imóveis para a população em geral.

Palavras chaves: design, chapas, vedação

Abstract: The timing of the construction of a building generally has increased run because of the handwork. The act of building a house is laborious and accumulates a large waste of construction material. Thus, the designer enters 
the area of housing construction with the goal of helping professionals in architecture and civil engineering projects in developing industrially designed product, thus facilitating the construction stage. One of the processes that demand more time for implementation and is a major producer of rubble is the construction of partition walls, including those located internally in the property, be it home or apartment. The time and the generation of debris can be reduced with the use of industrialized internal partition walls. This article then discusses the characteristics of the internal vertical fence construction system that uses plates of mineralized wood, internationally termed as WWCB wood wool cement board. Wood plaques mineralized draw attention when a report to the market as an eco-product. Consisting of reforestation wood or scrap of furniture and timber companies, she makes up a product design for efficient sealing. This opens the eyes of the professionals in the design field related to housing by proving a good ally in the quest for sustainable construction of buildings for the general population.

Keywords : design, plates, sealing

\section{INTRODUÇÃO}

O presente artigo tem por objetivo abordar a atuação do designer na concepção de produtos voltados à arquitetura e suas contribuições para esta área, tendo em vista os problemas presentes onde há a necessidade de dividir ambientes internos em imóveis residenciais. Esses problemas principalmente dizem respeito à indisponibilidade, no mercado, de um produto que aperfeiçoe a construção das divisórias internas a um preço condizente, com diminuição de tempo de execução e com minimização na geração de entulhos.

A arquitetura brasileira há tempos não sofre uma considerável alteração quanto aos seus métodos e processos construtivos, não por carência de novas tecnologias, mas por características culturais, falta de atualizações das empresas do ramo construtivo brasileiro e, sobretudo, por problemas socioeconômicos. Estes atrasos abrangem o uso de mão de obra com baixa qualificação e materiais e recursos muitas vezes inadequados às necessidades da obra.

As características acima descritas são verificadas em tarefas de levantamento de paredes externas e internas de alvenarias, principalmente, e também nas instalações dos sistemas hidráulico e elétrico, que geram grande volume de repetição de trabalho, geração de entulho e de desperdício de material, em virtude dos cortes que se fazem nas paredes para a colocação dos dutos, refletindo também no acabamento. Isso além da grande quantidade de tempo utilizada por estes processos.

Neste tema, estuda-se a vedação vertical interna industrializada, observando suas características construtivas e enfocando a utilização destas produzidas industrialmente. As vedações de estudo foram as produzidas com chapas de madeira mineralizada.

As chapas de madeira mineralizada justificam sua escolha para estudo por ser o sistema construtivo de vedação vertical interna industrializada e por apresentarem características de eco-produto, tornando a habitação mais próxima de um ideal sustentável. 


\section{A CONSTRUÇÃO DE IMÓVEIS NACIONAIS}

Segundo Bittencourt apud Riccetti (2004), mesmo nos países mais desenvolvidos a indústria da construção de imóveis também é uma das mais atrasadas quando comparada com outros setores industriais, caracterizando-se como complexa por ser o resultado da interligação de setores produtivos de diferentes áreas.

Com o processo tradicional de tijolos a qualidade final das paredes fica muito dependente da qualificação do trabalho do operário que as executa. Um número maior de produtos industrializados ou semi-industrializados que possibilitam um maior grau de liberdade de montagem e acabamento ficando, assim, previsível sua qualidade final.

A industrialização apresenta-se como alternativa tecnológica para potencializar a racionalização dos processos e elementos construtivos. Ao normalizar os procedimentos de produção, criam-se padrões e controles de qualidade a serem empregadas na construção, o que contribui para melhorar as condições de trabalho, aumentar a produtividade, gerando confiabilidade e garantias nos prazos de entrega. $A$ racionalização da produção busca também minimizar desperdícios, pois grande parte dos materiais empregados na construção de uma edificação é de origem não renovável.

A interação entre o design e a arquitetura possibilita inovar e explorar a capacidade de adequação das soluções estruturais, tornando possível novas formas e composições materiais, otimizando recursos e criando símbolos de uma época marcada pelo avanço tecnológico aliados a uma consciência ecológica. Em décadas recentes, reflexões teóricas e mesmo experiências práticas em projetos arquitetônicos apresentaram-se como estratégia novas de montagem. Montar e desmontar, flexibilizando não só a construção, mas a utilização ou reutilização da edificação.

Também a dificuldade em gerar usos duradouros de apartamentos residenciais tem se constituído em uma das mais sérias limitações da habitação produzida nos últimos 50 anos, sendo provavelmente um dos mais sérios prejuízos da qualidade da habitação confrontada atualmente. O autor dessa afirmação, Callado (1995), sustenta sérias críticas à forma tradicional de projetar, baseadas na perspectiva funcionalista clássica.

A reabertura de um comércio franco e ativo com o resto do mundo nos coloca frente a novas possibilidades e mecanismos. Edificações mais ágeis na sua construção e que, ao mesmo tempo reduzam de forma objetiva o "resíduo de obra", não só são desejáveis como viáveis. Esses componentes e técnicas articuladas permitem a liberdade de projetar qualquer obra baseada em montagem, coordenação modular e produtos adequados.

Ao pesquisar novas alternativas para a construção local, transitando pela industrialização leve, articulada e disponível para a intervenção individual, com novos materiais de alta performance, descobrem-se sistemas de vedações verticais com placas de madeira mineralizada.

Conforme Johansson (1994), o uso destes materiais, entretanto, é limitado em países como o Brasil. O autor destaca que as razões podem ser as características do produto são pouco conhecidas e por isso pouco valorizadas e que a utilização de materiais especiais exige adaptação nos métodos tradicionais. A produção e utilização 
de placas leves é viável, está plenamente testada há praticamente 100 anos, e tem sua versatilidade comprovada por um número significativo de $\mathrm{m}^{2}$ construídos ao redor do mundo.

No Brasil ainda se faz necessário a realização de pesquisas que viabilizem a implantação em larga escala de sistemas construtivos industrializados de vedações verticais internas. A disseminação do conhecimento de novas tecnologias e o emprego de sistemas construtivos racionalizados possibilita desenvolver processos industrializados que atendam as exigências de sustentabilidade tão necessários em nossos tempos.

\section{O DESIGN COMO FERRAMENTA}

A origem do termo design pode ser remetida ao contexto do século XIX, a partir da produção mecanizada enquanto desdobramento da Revolução Industrial. O design, enquanto concepção e planejamento qualifica-se como sendo o distanciamento da execução, em oposição aos objetos artesanais (CHARLOTTE \& FIELL apud AZEVEDO, 1998).

Segundo Lobach (2001), o design industrial é o processo de adaptação dos produtos de uso fabricados industrialmente às necessidades físicas e psíquicas do usuário ou grupo de usuários. Compete ao designer industrial elaborar as funções dos produtos mediante as quais se atendem as necessidades psíquicas do usuário. Ele define o termo design como sinônimo de projeto, ideia ou plano para a solução de um problema determinado. Desta forma, o autor atribui ao design a função de configuração do entorno, e esse conceito geral se desdobra em vários tipos de configuração do ambiente que cerca o homem, de forma a suprir suas necessidades.

Dorfles (1984) propõe alargar o conceito de design, de modo a fazê-lo incluir não só a criação de objetos em série, mas, em geral, todos os elementos planificados em série, estendendo, portanto, o seu âmbito até boa parte da arquitetura. Atualmente a concepção de um produto para arquitetura é o objeto de intervenção de diversas áreas de conhecimento, o design industrial, que participam atuando de diferentes maneiras dentro de suas especialidades para o planejamento e produção.

Löbach (2001) afirma que o design é a ferramenta com a qual se pode contar para a melhoria do padrão de qualidade dos produtos. É no design que todas as qualidades desejadas são planejadas, concebidas, especificadas e determinadas para o produto, amarradas a sua natureza tecnológica e aos demais processos que fazem parte de sua produção.

Trazendo este conceito para o universo da arquitetura, pode-se pensar a atuação do designer industrial nos projetos de produtos que vão compor o sistema objetual da moradia passando pela concepção de elementos industrializados utilizados na fase de construção da edificação, que é onde se encaixam as vedações verticais, e, até mesmo, na configuração de sistemas construtivos a serem posteriormente empregados na confecção de projetos arquitetônicos.

\section{CARACTERISTICAS DAS VEDAÇÕES VERTICAIS INTERNAS}

Segundo Barth e Vefago (2007) o aumento do grau de industrialização é função da racionalização e da mecanização, podem substituir gradativamente o trabalho 
humano pela máquina, com os objetivos de diminuir ou eliminar os desperdícios e aumentar a produtividade. Deste modo, pode-se maximizar a fabricação de produtos com o mínimo de insumos.

Nas culturas com maior domínio tecnológico, tem-se uma maior utilização dos componentes industrializados constituídos por painéis de vedação de pequenas e grandes dimensões, como também por componentes leves empregados para compor o sistema de vedação vertical interna.

As vedações verticais internas têm como função principal a proteção dos ambientes contra os agentes agressivos externos. A esta função, está associado o cumprimento de requisitos de desempenho, cujos principais encontram-se listados na tabela 4.1.

Tabela 4.1 - Requisitos de desempenho e características funcionais das vedações verticais.

\begin{tabular}{|c|c|}
\hline REQUISITOS DE DESEMPENHO & $\begin{array}{l}\text { CARACTERISTICAS } \\
\text { FUNCIONAIS }\end{array}$ \\
\hline - Segurança estrutural & - Resistência mecânica \\
\hline - Isolação térmica & - Deformabilidade \\
\hline - Isolação acústica & - Estabilidade dimensional \\
\hline - Estanqueidade & - Propriedades térmicas \\
\hline - Segurança ao fogo & - Resistência à transmissão sonora \\
\hline - Estabilidade & - Resistência ao fogo \\
\hline - Durabilidade & - Resistência a penetração de água \\
\hline - Estética & - Resistência a agentes agressivos \\
\hline - Economia & $\begin{array}{l}\text { - Custos adequados de produção e } \\
\text { manutenção }\end{array}$ \\
\hline
\end{tabular}

Fonte: Franco (1998).

\section{VEDAÇÃO VERTICAL INTERNA COM PLACAS DE MADEIRA MINERALIZADA}

Ainda pouco conhecidas no mercado brasileiro, as placas cimentícias de madeira mineralizada utilizam fibras longas de madeira selecionada, que recebem a adição de cimento, após sofrerem um processo de mineralização. A mistura é depositada em fôrmas, que são prensadas em diferentes dimensões e espessuras, adequadas aos diversos tipos de utilização. Este material, além de excelente qualidade termo-acústica, tem grande resistência e durabilidade. Pode receber qualquer tipo de acabamento, inclusive reboco, e seu manuseio é simples e fácil, pois permite ser serrado e trabalhado com ferramentas comuns. As possibilidades de aplicação são diversas, como forros, divisórias e revestimentos térmicos e acústicos; paredes divisórias de proteção ao fogo; asas pré-fabricadas e habitações populares; e alvenarias internas e externas (JOHANSSON, 1994).

Historicamente as placas feitas com palha de madeira (maravalhas), gesso e água foram patenteadas na Alemanha já em 1880. Durante a década de 1910 começou na Áustria a produção de placas de palha de madeira com magnesita como agente aglutinador (patenteado em 1908).

A magnesita apresentou melhor durabilidade que o gesso. $O$ cimento Portland foi introduzido no fim dos anos 20 e é hoje o mais comum aglutinador, fato pelo qual 
elas são hoje comumente chamadas de placas de cimento de palha de madeira e, na América do Norte, placas de maravalhas de cimento (CEB). Neste trabalho adotaremos a denominação nacional de placa de madeira mineralizada.

Até o século 20 existiam apenas alguns equipamentos básicos disponíveis para a produção de madeira mineralizada. O tratamento das matérias-primas, o trabalho pesado para a distribuição de material nos moldes, a remoção dos moldes para o próximo dia e empilhamento etc, tudo tinha de ser feito à mão por um grande número de trabalhadores. Apenas na segunda metade do século passado que a disponibilidade de equipamentos automáticos para empilhamento e demais atividades da fabrica tornaram-se disponíveis. Isso significa que só recentemente o processo de fabricação das placas de madeira mineralizada foi totalmente automatizado para todos os equipamentos.

A técnica para produzir placas de madeira mineralizada, principalmente aglutinadas com cimento, espalhou-se rapidamente da Áustria e Alemanha para outros paises europeus e também para a América do Norte. Um grande aumento na produção ocorreu durante anos antes e depois da segunda guerra mundial. Posterior a isso as placas de madeira mineralizada espalharam-se para lugares geograficamente ainda mais longes. No começo, as placas de madeira mineralizadas aglutinadas com cimento era produzidas manualmente em pequenas fábricas. $O$ equipamento limitava-se a máquinas de retalhamento da madeira, para produzir a palha de madeira, e um misturador. A fabricação ficou gradativamente mais mecanizada no decorrer dos anos, com capacidade de produção significativamente elevada. Fábricas modernas de placas de madeira mineralizadas são hoje totalmente mecanizadas o que permite que aproximadamente 15 pessoas consigam produzir até $150 \mathrm{~m}^{3}$ de placas por dia.

A madeira mais comumente utilizada, segundo Johansson (1994), para a confecção das placas provém de coníferas, principalmente pinheiros e abetos. Durante os anos 60, grande número de outras espécies foram testadas, incluído madeiras tropicais. Nisso levantou-se um grande número de espécies de diversos países, o que levou à produção de placas de madeira mineralizada em outros continentes. Existe produção atualmente na África (Gama, Malawi, Namíbia, Zâmbia), Ásia (Burma, Índia, Indonésia, Japão, Malásia, Filipinas, Taiwan, Tailândia) e América Latina (Brasil, México, Panamá, Peru e Venezuela).

Com poucas exceções, até 1960 o produto apresentava reduzida qualidade, devido a distribuição em moldes e escassez de método controlado de dosagem, etc. Depois da produção mecânica, tornou-se aceito, o número de diferentes métodos de aplicação aumentou, devida a superior qualidade, a simplicidade dos moldes e produção em massa permitindo preços baixos.

As placas são produzidas no Brasil na cidade catarinense de Blumenau pelas empresas Movimax-Epex e Garbe. A precursora desta atividade iniciada em $1956 \mathrm{em}$ Porto Alegre, no Rio Grande do Sul, foi a Movimax Epex, ainda com o nome de Climatex. O empresário alemão Werner Dopheide foi quem trouxe a tecnologia da Europa, onde o material é utilizado há muitos anos e teve sua patente estabelecida em 1880, na Alemanha.

\subsection{Processo de fabricação das placas}

Segue abaixo algumas fotos e descrições da planta para a produção de placas de WWCB totalmente automatizado. A imagem 5.1 representa a planta da produção. 


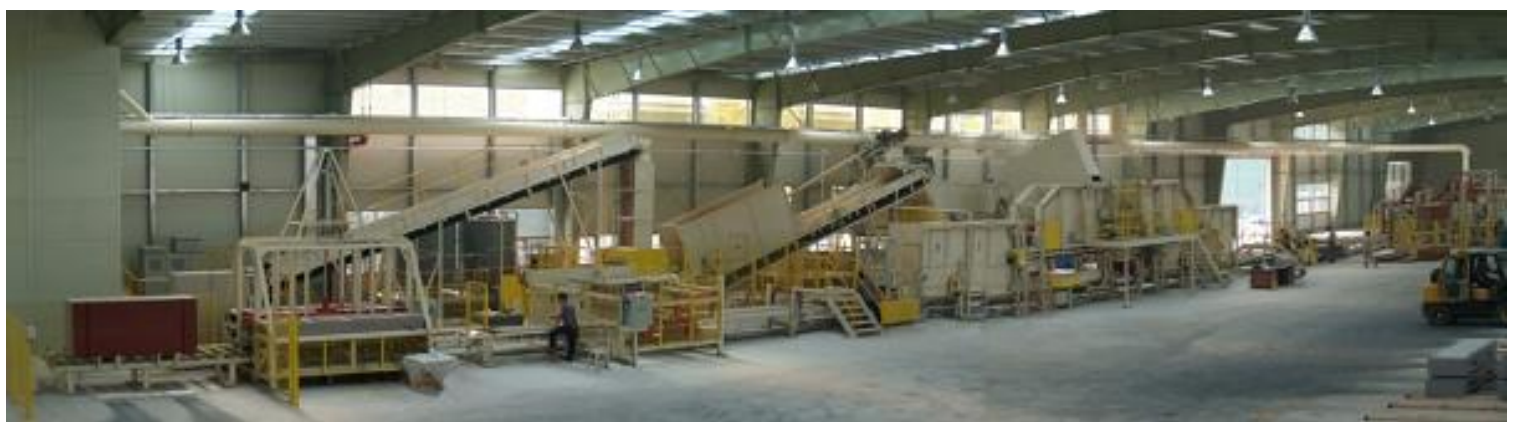

Figura 5.1 - Planta da fábrica de placas de madeira mineralizada. Fonte: Eltomation Eltomation (2014)

O primeiro passo para a produção das placas de madeira mineralizada é o desfiamento das toras de madeira até formar uma lã. A Figura 5.2a mostra Eltomatic CVS-16 que faz o retalhamento até atingir a Lã de madeira. Esta máquina tem 16 facas em um disco giratório e substitui cerca de 10 homens trabalhando de forma convencional com as máquinas com duas facas, que estão mostradas na figura 5.2b.

Devido aos acidentes ocasionais com estas máquinas convencionais elas agora estão proibidas.Depois a lã segue para a submersão em solução salina. A figura 5.3a apresenta a unidade de submersão contínua através da qual o fluxo de Lã de madeira seca é brevemente mergulhado em uma solução de sal de baixa concentração. Alguns produtos químicos, em muitos casos, silicato de sódio (água de vidro), são utilizados para estimular a aderência do cimento à madeira.
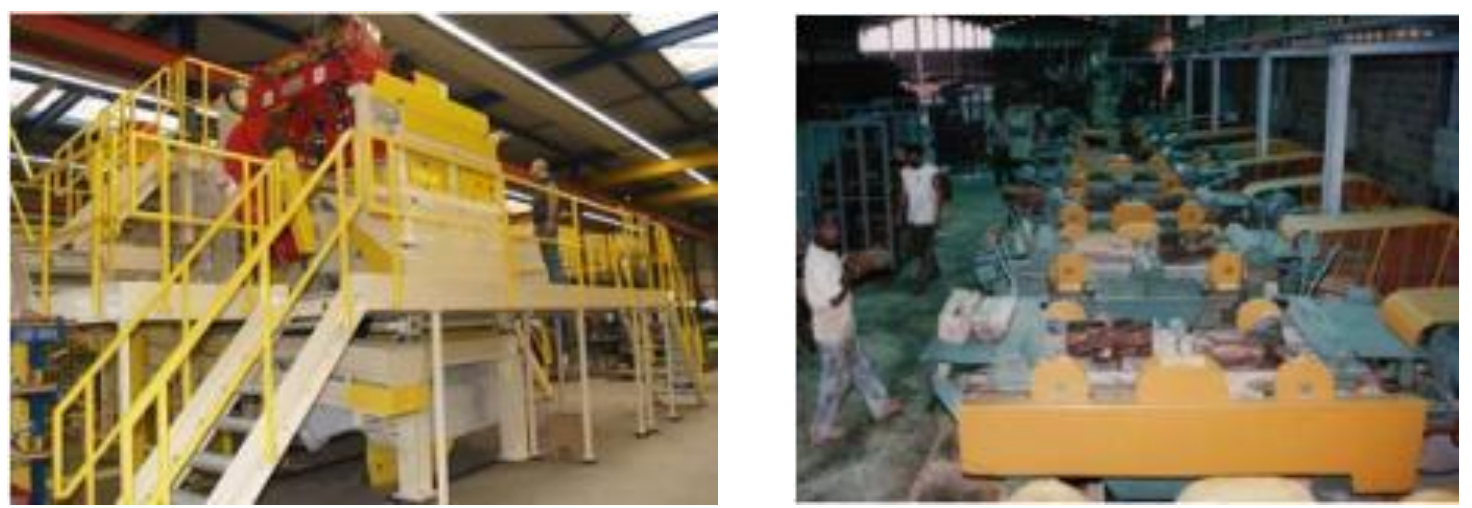

Figura 5.2: a - Eltomatic CVS-16, produção de lâ de madeira e b - produção de lâ de madeira com máquina de duas facas. Fonte: Eltomation (2014)
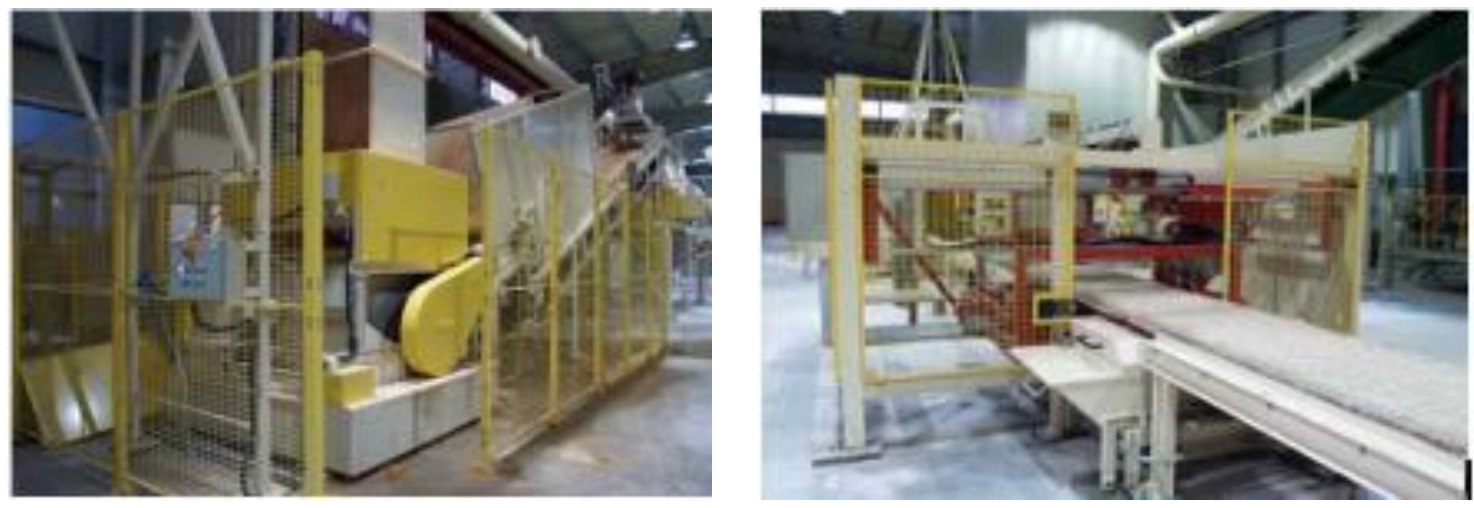

Figura 5.3: a - Submersão da madeira e b . Fonte: Eltomation (2014) 
Em um misturador adiciona-se uma pequena quantidade de cimento sobre a lã de madeira. O cimento proveniente do silo de cimento fora do prédio cai no misturador de cimento e lã. A lã com o cimento é distribuída sobre uma mesa lateral ao misturador. A figura 5.3b mostra a lã de madeira antes de ser moldada e prensada. Esta máquina corta a placa pré-prensada em exatamente as medidas do molde. A prensa hidráulica produz a compactação das placas e o corte padroniza o tamanho das mesmas, conforme mostrado na figura 5.4a.
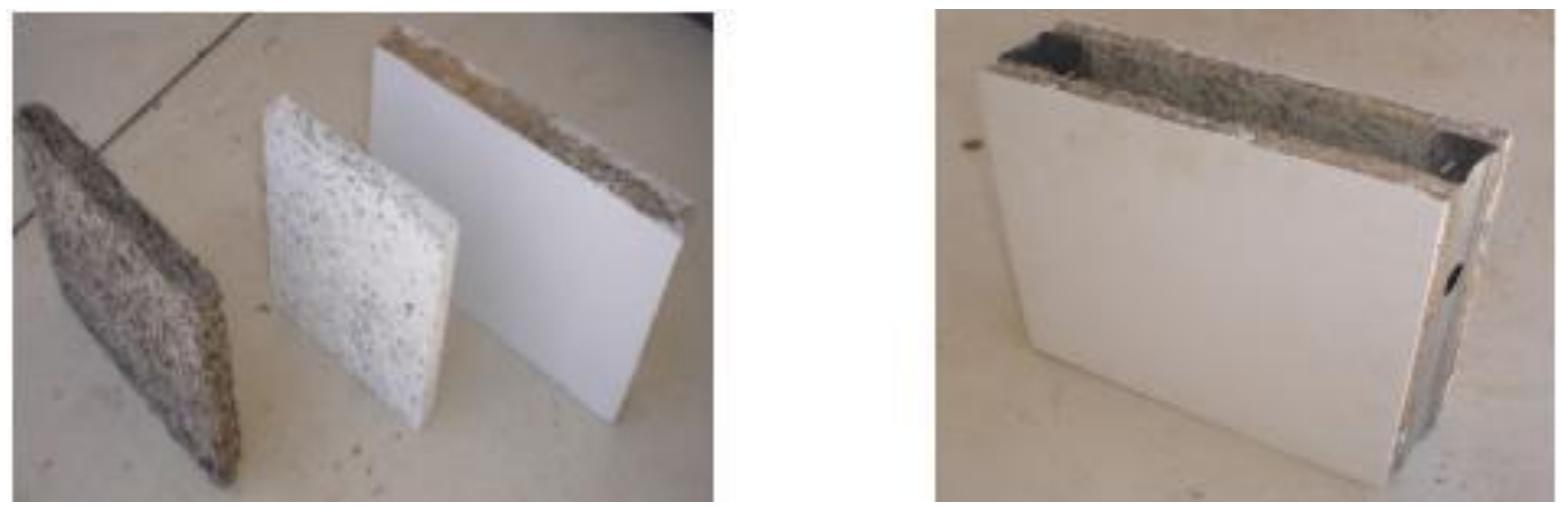

Figura 5.4 - as placas de madeira mineralizada e b- painel de vedação com placas de madeira mineralizadas. Fonte Camillo (2010).

\section{CONSIDERAÇÕES FINAIS}

$\mathrm{Na}$ análise do sistema construtivo citado, vemos que os materiais que o compõe já definem, por si, que as chapas de madeira mineralizada são um ótimo investimento para a inovação das vedações verticais internas industrializadas. A madeira é um bem renovável e de fácil cultivo e processamento.

Além disso, ela torna as vedações verticais internas mais próximas de um ideal sustentável. Os projetistas ligados à área da construção habitacional devem usar este material e ousar nas propostas de seu emprego. Mais um passo em direção a melhor utilização dos materiais que a natureza nos oferece.

O sistema construtivo citado pode ser beneficiado com a elaboração de um projeto de design, pois segundo Löbach (2001) o design é a ferramenta com a qual se pode contar para a melhoria do padrão de qualidade dos produtos. É no design que todas as qualidades desejadas são planejadas, concebidas, especificadas e determinadas para o produto, amarradas a sua natureza tecnológica e aos demais processos que fazem parte de sua produção.

\section{REFERÊNCIAS}

ADAMS, S. Construtividad. Barcelona: 1a Edição. Ediciones CEAC, 1990.

AZEVEDO, W. O que é design. São Paulo: Brasiliense, 1998. 
BALDAUF, A. S. F. Contribuição à implementação da coordenação modular da construção no Brasil.2004. Dissertação (Mestrado em Engenharia) - Universidade Federal do Rio Grande do Sul, Porto Alegre, 2004.

BANET. Informações sobre suas atividades. Disponível em: <http://www.banet.com.br/construcoes/index.htm>. Acesso em: 29 de abril 2014.

BARTH, F. Las fachadas de hormigón arquitetónico y GRC: Aplicación y comportamiento de los cerramientos prefabricados. 1997. (Doutorado em Arquitetura) - ETSABUPC. Barcelona. ES. 1997.

BARTH, F. VEFAGO, L.H (2007) Tecnologia de Fachadas Pré-fabricadas. Editora Letras Contemporâneas Oficina Editorial Ltda. Florianópolis.

BARTH, F.; FACCIO, J; BASTOS, P. GRC Panels on The Façades of The Catedral da Sé. In: GRC2003- 13 th International Glassfibre Reinforced Concrete Congress. 2003a. Barcelona.

BAXTER, M. Projeto de produto: guia prático para desenvolvimento de novos produtos. 1a ed. São Paulo: Edgard Blücher Ltda, 1998.

BRANDÃO, D.Q. Avaliação da qualidade de arranjos espaciais de apartamentos baseada em aspectos morfo-topológicos e variáveis geométricas que influenciam na racionalização construtiva. Ambiente Construído, Associação Nacional de Tecnologia do Ambiente Construído. Porto Alegre, v. 6, n. 3, p. 53-67 2006.

BÜRDEK, Bernhard E. História, Teoria e Prática do Design Industrial. Barcelona: Ed. Gustavo Gili, 2006.

CALLADO, J. The architect's perspective. Urban Studies, Essex, v. 32, n. 10, p. 16651677, 1995.

CAMILLO, Maiara G. D. Análise da Utilização de Chapas e Placas Industrializadas nas vedações verticais internas em Construções Residenciais na região Sul do Brasil. Dissertação (Mestrado em Arquitetura e Urbanismo) - universidade Federal de Santa Catarina - UFSC. Florianópolis, 2010

CÉSAR, Sandro F. Chapas de madeira para vedação vertical de edificações produzidas industrialmente. 2002. 302 p. Tese (Doutor em Engenharia de Produção) Universidade Federal de Santa Catarina, Florianópolis, 2002.

DORFLES, Gillo. O design industrial e sua estética. Lisboa: Presença, 1984.

DORFMAN, Gabriel. Flexibilidade como balizador do desenvolvimento das técnicas de edificações no século XX. 2002. 9 p. Artigo (Pós graduação em Arquitetura e Urbanismo) - Universidade de Brasília. Brasília. 2002. 
ELTOMATION bv, holanda: site da internet da http//:www.eltomation.com, acesso em abril de 2014.

FOLZ, Rosana R. Mobiliário na habitação popular. 2002. 240 p. Dissertação (Mestrado em Arquitetura e Urbanismo) - Escola de Engenharia de São Carlos da Universidade de São Paulo. São Paulo. 2002

FRANCO, L.S. O projeto das vedações verticais: características e importância para a racionalização do processo de produção. In: Tecnologia e gestão na produção de edifícios: Seminário vedações verticais. Anais. São Paulo: EPUSP, 1998.

HERBERT, G. Designing for human behavior: some performance guidelines for the design and evaluation of environmental spaces in the dwelling. In: LICHFIELD, Nathaniel. New trends in urban planning. Dan Soen (Ed.). Oxford: Pergamon, 1979. p. 198-216.

JOHANSSON, Erik - Woodwool Slabs: Manufacture, Properties and Use. Lund University - Centre of Habitat Studies, Suécia, 1994

KOTLER, P. Marketing Management - Analysis, Planning, Implementation, and Control. Londres: Prentice-Hall. 1997.

LÖBACH, Bernd. Design indutrial: bases para a configuração dos produtos industruiais. 1a ed. São Paulo : Edgard Blücher Ltda, 2001

ORNSTEIN, S. W. Desempenho do ambiente construído, interdisciplinaridade e Arquitetura. São Paulo: FAU/USP, 1996. 54 p.

RABENECK, A.; SHEPPARD, D.; TOWN, P. Housing flexibility/adaptability: Architectural Design, Londres, v. 49, p. 76-90, Feb. 1974.

REIS, A. T. L. Avaliação de alterações realizadas pelo usuário no projeto original da habitação popular. In: ENCONTRO NACIONAL DE TECNOLOGIA DO AMBIENTE CONSTRUÍDO, 6., 1995, Rio de Janeiro. Anais... Rio de Janeiro: ANTAC, 1995. v. 1, p. 319-324.

RICCETTI, Teresa. A evolução da habitação e sua paisagem doméstica. Rio de janeiro: Anais P\&D Design, 2004

ROSSO, T. Teoria e prática da coordenação modular. São Paulo. Faculdade de Arquitetura e Urbanismo - Universidade de São Paulo. 1976.

SOUZA, U. E.L. de. Produtividade e custos dos sistemas de vedação vertical. In: Tecnologia e gestão na produção de edifícios: seminário vedações verticais. Anais. São Paulo: EPUSP, 1998. 
SOEN, D. Habitability: occupant's needs and dwelling satisfaction. In: LICHFIELD, Nathaniel. New trends in urban planning. Dan Soen (Ed.). Oxford: Pergamon, 1979. p. 119-132.

SULLIVAN, B. J. Industrialization in the building industry Van Nostrand Reinhold, N. York, 1980

SZÜCS, C.P. Critérios de projeto para a autoconstrução em madeira. In: Encontro Brasileiro em Madeira e em Estrutura de madeira. 1992, São Carlos. Anais... São Carlos: LaMEM / EESC /USP. 1992.

WEINSTEIN, A. Segmentação de mercado. São Paulo: Atlas, 1995. p. 238. 